\title{
Ameliorative Effect of Borage Seeds Oil against Radiation- Induced Hepatotoxicity in Rats
}

\author{
Mohamed M. Rezk ${ }^{1}$, Hazem, K.A. Sarhan ${ }^{2}$ and Amal A. A. Ammar ${ }^{2}$ \\ ${ }^{1}$ Geological Isotopes Dept., Nuclear Materials Authority \\ ${ }^{2}$ Medical and Radiation Research Dept., Nuclear Material Authority, Cairo, Egypt
}

\begin{abstract}
Background: Oxidative stress is known to be a key factor in several diseases and was reported as a result of radiation exposure in human and experimental animals. Borage (Borago officinal L.) oil contains a high percentage of $\gamma$-linolenic acid, which reported as a preventive treatment of a wide range of disorders. Aim: The present study was designed to determine the possible protective effects of borage seeds oil against gamma $(\gamma$ - $)$ radiation induced oxidative stress in male rats.Materials and Methods: Thirty rats were divided into five groups (6 rats each): Control, irradiated; rats were exposed to (6.5 Gy) of whole body $\gamma$-radiation, borage seeds ( $50 \mathrm{mg} / \mathrm{kg} \mathrm{b}$.wt), irradiated borage treated pre-irradiated and borage treated post-irradiated. Serum aspartate aminotransferase (AST), alanine aminotransferase (ALT), gamma glutamyl transferase (GGT) levels, as well as serum and hepatic reduced glutathione (GSH), superoxide dismutase (SOD) and lipid peroxide (malondialdehyde) (MDA) levels were assessed.

Results: The results showed that, activities of GSH were highly significant decrease, while marked highly significant increase in MDA due to irradiation. Supplementation with BO before or treated after irradiation, exerted marked amelioration of irradiation induced disturbances in all the investigated parameters. Therefore, borage could have a beneficial role in modulating oxidative stress by improving the natural antioxidant mechanism.

Conclusion: borage has a beneficial role in reducing hepatotoxicity and oxidative stress induced by radiation exposure.
\end{abstract}

Keywords: Borage seeds oil; $\gamma$-irradiation; Antioxidant; Hepatotoxicity.

\section{Introduction}

Radio-therapy is one of the most common treatment modalities for human cancer and it affects not only malignant tumors but also surrounding normal tissues. Because liver is a highly radiosensitive organ ${ }^{(1)}$, irradiation of the non-tumor compartment of the liver may cause cell damage.

Antioxidants have the capacity to reduce harmful effects of radiation on normal tissues. Antioxidants supplements reduce the treatment-related adverse effects, which occur during radiation therapy by overcome the oxidative damage to normal cells. The use of traditional plant-based preparations in remedial therapeutic and preventive medicines has been developed. Borage (Borago officinalis L.) from Boraginaceae family is an annual herbaceous plant with nutritional value used in traditional medicine and culinary uses in some countries ${ }^{(2)}$. Borage seeds oil contains mainly triacylglycerol (95\%) consisting of C16-C20 fatty acids, while $5 \%$ presents minor components composed of tocopherols, flavonoids, phospholipids, sterols, free fatty acids and also mono-and diacylglycerols. Several classes of these components act as antioxidants ${ }^{(3)}$. Borage seeds oil is the richest plant source of $\gamma$-linolenic acid (GLA) which is used as dietary supplement for prevention and/or treatment of various degenerative pathologies illnesses $^{(2)}$. GLA has also been reported to suppress tumor growth in vitro, improve oxygenation status, exert antiinflammatory activity and display beneficial effects in the early stages of sepsis ${ }^{(4)}$. In view of these considerations, the objective of the present study was to evaluate the efficacy of borage in the modulation of oxidative stress, biochemical and histopathological disorders in the liver of irradiated rats.

\section{Materials and Methods}

\section{Plant Material}

Borage seeds (Borago officinalis L.) were obtained from Faculty of Sci., Ain Shams University, Cairo, Egypt.

\section{Extraction of oil from Borage Seeds}

Dry borage seeds $(750 \mathrm{~g})$ were crushed using a commercial blender and then subjected to cold pressing. In this method, oil was extracted by continuous screw-pressers (Carver Press, USA) without any chemicals for $20 \mathrm{~min}$ at a pressure of $49.0 \mathrm{MPa}$. 


\section{Experimental animals}

Male albino rats $(160 \pm 20 \mathrm{~g})$ were purchased from the Egyptian Holding Company for Biological Products and Vaccines (Cairo, Egypt) and used for the different investigations carried out in the present study. Rats were acclimated to controlled laboratory conditions for two weeks. Rats were maintained on rodent diet and tap water ad libitum. The rodent control diet is composed of $15 \%$ casein, $10 \%$ corn oil, $5 \%$ cellulose, $4 \%$ salt mixture, $1 \%$ vitamins mixture and starch $65 \%$.

\section{Radiation facility}

Whole body gamma irradiation of rats at a dose level of 6.5 Gy was performed using a Canadian Gamma Cell-40, (137Cs) (Atomic Energy of Canada Ltd, Ottawa, Ontario, Canada), located at the National Center for Radiation Research and Technology (NCRRT), in Nasr City, Cairo, Egypt. The dose rate of the irradiation process was 0.45 $\mathrm{Gy} / \mathrm{min}$ at the time of the experiment calculated according to the dosimeter department in the NCRRT.

\section{Experimental Design}

Rats $(n=30)$ were divided into five groups (6 rats/group), all groups fed the standard AIN$93 \operatorname{diet}^{(6)}$, and given water ad libitum. The following scheme explained the experimental design: Control group; rats (non-irradiated and non-treated) received orally $0.5 \mathrm{ml}$ of distilled water with two drops of Tween-80, Irradiated group (Irrad); rats were exposed to single sub-lethal dose $(6.5 \mathrm{~Gy})$ of whole body $\gamma$-radiation and received orally $0.5 \mathrm{ml}$ of distilled water with two drops of Tween-80,

Borage oil group (BO); rats (non-irradiated) received $50 \mathrm{mg} / \mathrm{kg}$ b.wt $/$ day $\mathrm{BO}^{(7)}$, through an intragastric gavage dissolved in $0.5 \mathrm{ml}$ of distilled water with two drops of Tween-80. Irradiated BO treated pre-irradiated group; rats received the same gavage dosage of BO orally started 3 hours before irradiation for 2 weeks. Irradiated BO treated postirradiated group; rats were administered orally with BO (50 mg / $\mathrm{kg}$ b.wt) daily, started the day after irradiation and continued till the end of the experiment ( 2 weeks after irradiation). Serum samples were collected for biochemical analysis and liver samples for biochemical examinations.

\section{Biochemical analysis}

After blood collection, rats of each group were sacrificed under anesthesia, the liver samples were removed immediately, washed twice with ice-cold phosphate buffer saline (PBS) and homogenized in 5 volume of phosphate buffer $(\mathrm{pH} 8.0,0.01 \mathrm{M})$ using a Polytron homogenizer (pt 3100) (five cycles of $10 \mathrm{~s}$ at $3000 \mathrm{rpm}$ ). Aliquots were prepared according to $^{(8)}$, and used for the assessment of GSH and MDA. Serum and hepatic of both LPO and GSH levels were determined according to ${ }^{(9,10)}$, respectively). Serum alanine aminotransferase (ALT), aspartate aminotransferase (AST) ${ }^{(\mathbf{1 1})}$, gamma glutamyl transferase (GGT) ${ }^{(\mathbf{1 2})}$ were determined.

\section{Histopathological Study}

After animals' dissections, liver was removed immediately and fixed in $10 \%$ formalin, then the tissues were washed and dehydrated in ascending grades of ethyl alcohol cleared in zylene and impregnated in paraffin for $1.5 \mathrm{~h}$ in the oven at $55^{\circ} \mathrm{C}$. Serial section, $5 \mu \mathrm{m}$ were cut and stained with Haematoxylin \& Eosin (H\&E) as described by ${ }^{(\mathbf{1 3})}$.

\section{Statistical analysis}

Data are expressed as Mean \pm SE. Data were assessed by paired t-test ${ }^{(\mathbf{1 4})}$.

\section{Results}

Data presented in tables $(1,2)$ showed that, serum and hepatic levels of MDA in irradiated rats showed significant increase compared with their corresponding levels in control group. However, both irradiated borage pre/post treated irradiated groups induced significant improvement in the serum and hepatic MDA when compared with their levels in irradiated group. In irradiated group, serum and hepatic GSH and SOD activities were significantly reduced two weeks post irradiation as compared with their corresponding levels in control group. However, both irradiated borage pre/post treated irradiated groups showed significant increase in GSH and SOD activities during the experimental periods as compared with irradiated group.

Data presented in table (3) showed that exposure of rats to $6.5 \mathrm{~Gy}$ of whole body $\gamma$ radiation induced a significant increase $(\mathrm{p}<0.001)$ in the activities of AST, ALT and GGT in irradiated rats compared to the corresponding levels in non-irradiated control rats two weeks post radiation 
Table (1): Effect of pre/post-treated borage on serum lipid peroxide (MDA) level, reduced glutathione (GSH) content and superoxide dismutase activity in irradiated rats.

\begin{tabular}{|l|l|l|l|l|l|}
\hline \multirow{2}{*}{ Parameters } & \multicolumn{5}{|l|}{ Experimental groups } \\
\cline { 2 - 6 } & Control & Irr. G & BO G. & BO+Irr. G & Irr.+BO G. \\
\hline $\begin{array}{l}\text { MDA } \\
(\mathrm{nmol} / \mathrm{ml})\end{array}$ & $72.5 \pm 6.6$ & $126.3 \pm 7.1 * * *$ & $70.8 \pm 6.1$ & $79.5 \pm 7.8$ & $93.4 \pm 7.7 *$ \\
\hline $\begin{array}{l}\text { GSH } \\
(\mathrm{mg} / \mathrm{dl})\end{array}$ & $68.0 \pm 6.9$ & $36.2 \pm 5.9 * * *$ & $69.0 \pm 5.6$ & $60.2 \pm 6.7$ & $50.0 \pm 4.0^{*}$ \\
\hline $\begin{array}{l}\text { SOD } \\
(\mathrm{g} / \mathrm{ml})\end{array}$ & $62.0 \pm 5.2$ & $30.4 \pm 2.6 * * *$ & $61.0 \pm 5.0$ & $51.6 \pm 4.3$ & $42.2 \pm 3.9 * *$ \\
\hline
\end{tabular}

Each value represents the mean of 6 rats $\pm S E$.

Significant different from the corresponding control at $* P<0.05$, $* * P<0.01$ and $* * * P<0.001$.

Table (2): Effect of pre/post-treated borage on hepatic lipid peroxide (MDA) level, reduced glutathione (GSH) content and superoxide dismutase activity in irradiated rats.

\begin{tabular}{|l|l|l|l|l|l|}
\hline \multirow{2}{*}{ Parameters } & \multicolumn{5}{|l|}{ Experimental groups } \\
\cline { 2 - 6 } & Control & Irr.G & BO G. & BO+Irr. G & Irr.+BO G. \\
\hline $\begin{array}{l}\text { MDA } \\
\text { (nmol/g } \\
\text { tissue) }\end{array}$ & $163.2 \pm 9.4$ & $255.7 \pm 10.8^{* * *}$ & $159.4 \pm 8.1$ & $200.9 \pm 12.0$ & $224.0 \pm 11.3^{* *}$ \\
\hline $\begin{array}{l}\text { GSH } \\
(\mathrm{mg} / \mathrm{g} \text { tissue) }\end{array}$ & $49.6 \pm 4.3$ & $32.6 \pm 2.8$ & $50.3 \pm 3.8$ & $45.3 \pm 4.0$ & $37.0 \pm 3.0^{*}$ \\
\hline $\begin{array}{l}\text { SOD (U/mg } \\
\text { protein) }\end{array}$ & $44.9 \pm 2.1$ & $29.8 \pm 1.8$ & $45.6 \pm 2.0$ & $38.1 \pm 2.7$ & $32.8 \pm 2.5^{*}$ \\
\hline
\end{tabular}

Legends as in table (1).

Table (3): Effect of pre/post-treated borage on serum transaminases (AST\&ALT) and gamma glutamyl transferase (GGT) levels in irradiated rats.

\begin{tabular}{|l|l|l|l|l|l|}
\hline \multirow{2}{*}{ Parameters } & Experimental groups \\
\cline { 2 - 6 } & Control & Irr.G & BO G. & BO+Irr. G & Irr.+BO G. \\
\hline $\begin{array}{l}\text { AST } \\
\text { (U/L) }\end{array}$ & $106.9 \pm 9.6$ & $156.5 \pm 11.4$ & $104.5 \pm 8.5$ & $128.0 \pm 9.4$ & $135.0 \pm 10.0 *$ \\
\hline $\begin{array}{l}\text { ALT } \\
\text { (U/L) }\end{array}$ & $42.0 \pm 4.2$ & $73.7 \pm 4.8$ & $41.2 \pm 4.1$ & $51.7 \pm 3.7$ & $59.4 \pm 3.4 * *$ \\
\hline $\begin{array}{l}\text { GGT } \\
\text { (U/L) }\end{array}$ & $4.3 \pm 0.3$ & $8.7 \pm 0.9$ & $4.2 \pm 0.5$ & $5.2 \pm 0.7$ & $5.5 \pm 0.9 *$ \\
\hline
\end{tabular}

Legends as in table (1). 

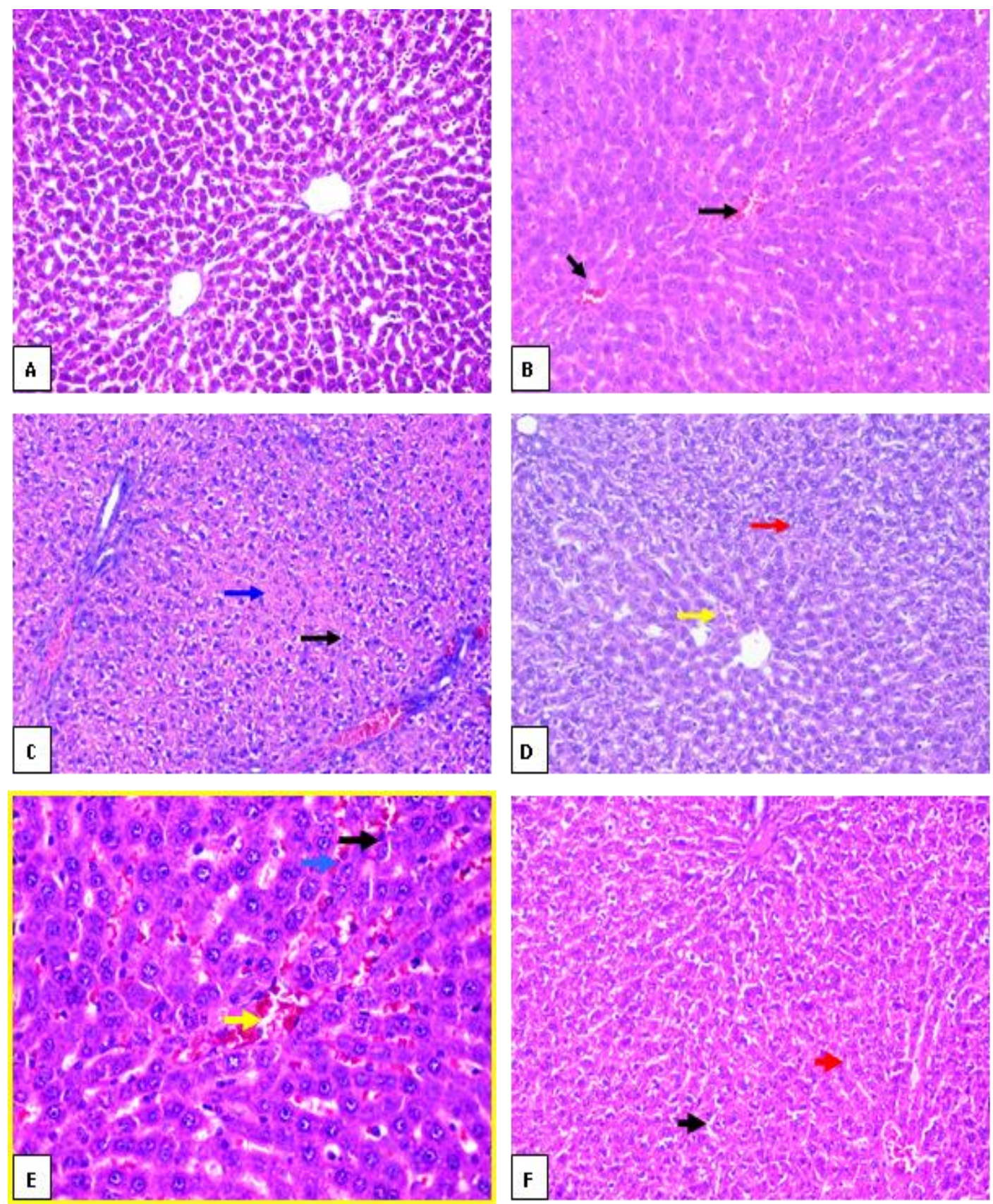

Fig.1. (A) (Group I-control) Showing normal histological structure of rat liver with preserved hepatic architecture, normal hepatocytes and central vein; (B) (GroupII-Borage.) Showing preserved hepatic architecture, hepatocytes within normal, with congested central vein (black arrows) (H\&E, x200). (C) (GroupIII-6.5Gy S.D.) Showing Showed partial loss of hepatic architecture, hepatocytes showed mild apoptotic changes (black arrow) and necrotic changes (blue arrow)(H\&E,x200). (D) (GroupIII-6.5Gy SD) Showing Marked hydropic degeneration, spotty necrosis (red) and angiogenesis (yellow) (H\&E,x200). (E) (GroupIV-Borage+6.5Gy FD) Showing preserved lobular architecture, mild hydropic degeneration (black) vessels (Yellow) and Congestion of sinusoids (blue)(H\&E,x400). (F) (Group V- 6.5Gy SD + Borage) Showing Preserved hepatic lobule architecture +mild hydropic degeneration (black) and mild spotty necrosis (red)(H\&E,x200). 
exposure. While both irradiated pre/post treated borage groups showed significant amelioration in the serum levels of ALT, AST and GGT when compared to the corresponding irradiated group. It was found that, pre-treated borage had more powerful effect against irradiation induced hepatotoxicity than post-treated borage.

\section{Histopathological observations}

Histopathological examination of the liver sections in normal control mice and that treated with borage showed preserved hepatic lobular architecture and central vein surrounded by hepatic cord of normal hepatocyte cells (Figure 1;A\&B). The liver of the irradiated groups showed loss of hepatic architecture, marked hydropic degeneration, central vein congestion and necrosis (Figure 1; C\&D). The histological changes induced by radiation were markedly reduced in the groups pre and after-treated with borage at dose $(50 \mathrm{mg} / \mathrm{kg}$ every other day) for one month. It was clear that the liver architecture was markedly preserved and showed marked decrease in the hydropic degeneration, central vein congestion and necrosis, indicating potent hepatoprotective action of borage (Figure $1 ; \mathrm{E} \& \mathrm{~F}$ ) in animals pre and aftertreated with borage in rats exposed to gamma radiation of 6.5Gy (single dose).

\section{Discussion}

All types of ionizing radiation generate ions which can lead to the formation of free radicals and reactive oxygen species (ROS). Excess production of free radicals or decrease in antioxidants level leads to oxidative stress. It is a harmful process that induces damage to cell structures, lipids, proteins, RNA and DNA which leads to number of diseases ${ }^{(15)}$. Reactive oxygen species (ROS) induce many changes in physiological and pathological states $^{\mathbf{( 1 6 )}}$. They may be toxic through attacking the molecular level directly or indirectly by generating secondary reactive species ${ }^{(17)}$. These radicals may cause biomolecules oxidative damage ${ }^{(18)}$. The use of plants, natural products are thoughts to be beneficial in protecting against radiation-induced damage, they are less toxic compared to synthetic compounds used at their optimum protective dose levels ${ }^{(\mathbf{1 9})}$. Hence the interests have always existed in development of potential drug of plant origin, been a good source of potent but non-toxic radioprotectors ${ }^{(20)}$. The aim of this study was to investigate the possible protective effect of borage against the disturbances induced by radiations in rat's liver. Borage oil is of great interest due to its high content of GLA ${ }^{(\mathbf{2 1})}$. This essential polyunsaturated fatty acid plays a role in health maintenance through involvement in cell membrane structure and synthesis of anti-inflammatory eicosanoids such as prostaglandins E1 which have antioxidant and hepatoprotective properties $^{(22)}$.

The present data revealed that gamma radiation exposure $(6.5 \mathrm{~Gy})$ resulted in significant acceleration in the oxidation of lipid by elevating the level of both serum hepatic MDA activities. The exposure to ionizing radiation increases the production of ROS and directs the irradiated cells into a state of oxidative stress that has been implicated in a variety of natural and pathological processes ${ }^{(23)}$. Radiation induced radiolysis of water in the aqueous media of the cells which leads to production of hydroxyl radicals $(\bullet \mathrm{OH})$ that interact with the polyunsaturated fatty acids in the lipid portion of biological membranes initiating the lipid peroxidation and finally damaged the cell membranes ${ }^{(24)}$. While, the observed decrease in the activities of serum and hepatic GSH content in $\gamma$-irradiated group in this study could be due to a feedback inhibition or oxidative inactivation of the enzyme protein caused by reactive oxygen species (ROS) generation, which in turn can impair the antioxidant defense mechanism, leading to an increased membrane $\mathrm{LPO}^{(40)}$.

On the other hand, the group of rats that received borage $(50 \mathrm{mg} / \mathrm{kg} / \mathrm{day})$ and exposed to gamma radiation showed an obvious reduction in hepatic MDA with significant elevation in hepatic GSH content in compared to irradiated-rats.

However, BO induced significant improvement in serum and hepatic antioxidant status. Previous studies indicated that borage seeds oil was one of the richest plants that contains $\gamma$-linolenic acid ${ }^{(6)}$. The high levels of $\gamma$-linolenic acid in BO might have accentuated the treating action of this oil, where $\gamma$-linolenic acid is needed for the synthesis of hormone-like prostaglandins, which regulate certain aspects of metabolism, protect against prooxidants induced membrane and cellular damage, and possess a modulatory action on the antioxidant status. 
Several studies evaluated the relationship between antioxidant activity of borage extract and its GLA content ${ }^{(26)}$. Both borage seed oil and GLA were able to desmutagenise the genotoxic activity of hydrogen peroxide by scavenging the ROS originated by the model genotoxicant used. The protective effect of BO on liver in this study can be related to its function of scavenging free radicals and to its high content of GLA ${ }^{(27)}$.

In the present study, the elevation in the activity of the serum enzymes ALT, AST and GGT after gamma-irradiation exposure could indicate occurrence of liver injury. The damage of cellular membranes of hepatocytes following exposure to ionizing radiation leads to an increase in the permeability of cell membranes and facilitates the passage of cytoplasmic enzymes outside the cells leading to the increase in the aminotransferase activities in liver and blood serum. On the other wise, treatment with oral borage against gamma radiation in this work efficiently trims down the elevated levels of serum biomarkers such as AST, ALT and GGT and these results in agreement with that of Chen-Yang $\boldsymbol{e t}$ al. (28). The significant reduction in the level of liver enzymes as results of borage supplementation could be attributed to the ability of borage as potent antioxidant to prevent liver damage by maintaining the integrity of the plasma membrane, thereby suppressing the leakage of enzymes into the serum.

In the present study, irradiation produced damage reflected by deleterious changes in the structure of liver tissues. These results agree with Kawashima $e t \boldsymbol{a l} .{ }^{(30)}$ who found that gamma irradiation induced injury, swelling, and pathological damage of rats' liver. The pretreatment with antioxidant agent prevents the injurious effect of irradiation on rats' liver. These findings may be due to the fact that exposure to radiation causes injury to blood vessels with degeneration and necrosis of hepatic parenchyma. Borage has a protective effect against morphological changes induced by $\gamma$-irradiation, this may be due to the fatty acids composition of $\mathrm{BO}$, which promises the useful protector against the production of free radicals induced by gamma irradiation ${ }^{(27)}$. Most of the histopathological lesions observed in $\gamma$ irradiated group were diminished to a large extent; where the normal architecture of the liver was partially restored in the pre- and after-treated group. The improvement is more pronounced in irradiated borage pre-treated than post-treated groups.

\section{Conclusion}

In light of this study, the results suggested that the high antioxidant properties of borage may be related to its $\gamma$-linolenic acid (GLA) contents and free radical scavenging activity. Also, the results demonstrated the effectiveness of borage in the protection of liver damage induced by $\gamma$-radiation exposure. Thus, the use of natural products as borage to treated hepatotoxicity could be important in clinical radiation therapy to protect human cells from radiation damage.

\section{References}

1-Chen Y, Zeng Z, Sun J et al. (2015): Mesenchymal stem cell-conditioned medium prevents radiation-induced liver injury by inhibiting inflammation and protecting sinusoidal endothelial cells. J. Radiat. Res., 56: 700-708.

2-Asadi-Samani M, Bahmani M. and RafieianKopaei M (2014): The chemical composition, botanical characteristic and biological activities of Borago officinalis: a review. Asian Pac J Trop Med., 7S1:S22-28.

3-Shahidi F and Shukla VKS (1996): Nontriacylglycerol constituents of fats and oils. INFORM., 7(11):1227-1232.

4-Pontes-Arruda A, Martins LF, de Lima SM, Isola AM, Toledo D, Rezende E, Maia M. and Magnan GB (2011): Enteral nutrition with eicosapentaenoic acid, gamma-linolenic acid and antioxidants in the early treatment of sepsis: results from a multicenter, prospective, randomized, double-blinded, controlled study: the INTERSEPT study. Crit. Care, 15(3): R144.

5-Philip GR, Forrest HN and George CF (1993): AIN - 76A rodent diet. J. Nutr., 123:1935-1951.

6-Reeves PG, Nielsen FH and Fahey GC (1993): AIN-93 Purified diets for laboratory rodents: Final report of the American Institute of Nutrition Ad Hoc Writing Committee on the Reformulation of the AIN-76. A Rodent diet. J. Nutr., 123:1939-1951.

7-Hamed ANE and Wahid A (2015): Hepatoprotective activity of Borago officinalis extract against $\mathrm{CCl} 4$-induced hepatotoxicity in rats. J. of Nat. Prod., 8:113-122.

8-Arafa HM, Abd-Ellah MF and Hafez HF (2005): Abatement by naringenin of doxorubic- 
induced cardiactoxicity in rats. J. Egypt. Nat. cancer Inst., 17 (4): 291-300.

9-Vashney $R$ and Kale RK (1990): Effect of calmodulin antagonists on radiation-induced lipid peroxidation in microsomes. Int. J. Radiat. Biol., 58 (5):733-743.

10-Jollow GL, Mitchell JR and Zampaghone N (1974): Bromobenzene induced liver necrosis, protective role of glutathione and evidence for 3,4- bromobenzene oxide as the hepatotoxic metabolite. Pharm., 11(3):151-169.

11-Reitman S and Frankel S (1957): A colorimetric method for the determination of serum oxaloacetic and glutamic pyruvic transaminases. Am J. Clin. Pathol., 28 (1):56-63. 12-Szewczuk A, Kuropatwa $M$ and Lang D (1988): Colorimetric method for assay of serum gammaglutamyltransferase activity with some Lgamma- glutamyl-carboxyanilides. Clin. Chim. Acta., 178(1):35-40.

13-Bancrofet $J$ and Stevens A (1977): Theory and practice of histological techniques. Chuchil Livingstone Edinburgh-London and New York, USA, p. 98.

14-Avram G (1964): "Quantitative Data." In: Biostatistics: An Introductory text. Chapter 2, page $53 \&$ 63. The MacMillan Company, New York, Collier MacMillan limited, London.

15-Valko M, Leibfritz D, Moncol J, Cronin MT, Mazur $M$ and Telser $J$ (2007): Free radicals and antioxidants in normal physiological functions and human disease, The International Journal of Biochemistry \& Cell Biology, 39:4484.

16-Tawfik SS, Abbady MI, Zahran AM and Abouelalla AMK (2006): Therapeutic efficacy attained with thyme essential oil supplementation throughout $\gamma$-irradiated rats. Egypt J. Rad. Applic., 19 (1):1-22.

17-Brenneisen $\mathbf{P}$, Briviba $K$, Wlaschek $M$, Wenk J and Scharffetter-Kochanek K (1997): Hydrogen peroxide increases the steady-state mRNA levels of collagenase/kkp-1 in human dermal fibroblasts. Free Rad. Bio. Med., 22(3):515-524.

18-Kowaltowski AJ and Vercesi AE (1999): Mitochondrial damage induced by condition of oxidative stress. Free Rad Bio Med., 26 (34):463-471.

19-Bhatia AL, Manda K, Patni S, Sharma AL (2006): Prophylactic action of linseed (Linum usitatissimum) oil against cyclophosphamideinduced oxidative stress in mouse brain. $\mathrm{J} \mathrm{Med}$ Food, 9(2): 261-4.
20-Blokhina O, Virolainen E, Fagerstedt KV (2003): Antioxidants, oxidative damage and oxygen deprivation stress: a review. Ann Bot., 91: 179-94.

21-Bandoniene D and Murkovic M (2002): The detection of radical scavenging compounds in crude extract of borage (Borago officinalis L.) by using an on-line HPLC-DPPH method. J Biochem. Biophys. Method., 53(1-3):45-49.

22-Lukivskaya OY, Zavodnik L, Knas M and Buko V (2006): Antioxidant mechanism of hepatoprotection by ursodeoxycholic acid in experimental alcoholic steatohepatitis. Adv. Med. Sci., 51:54-59.

23-Elkady AA and Mohamed ET (2016): Possible Role of Withania somnifera Against Gamma Radiation Induced Cardiotoxicity in Male Albino Rats. Pakistan J. Zool., 48:539-545. 24-Azab KH SH, Bashandy M, Salem M, Ahmed O, Tawfik Z and Helal H (2011): Royal jelly modulates oxidative stress and tissue injury in gamma irradiated male Wister Albino rats. $N$. Am. J. med. Sci., 3: 268-276.

25-Mihandoost E, Shirazi A, Mahdavi SR and Aliasgharzadeh A (2014): consequences of lethal-whole-body gamma radiation and possible ameliorative role of melatonin. Sci. World J., Article ID 621570.

26-Del Río-Celestino, M, Font $R$ and De HaroBailón A (2008): Distribution of fatty acids content in edible organs and seed fractions of borage (Borago officinalis L.). J. Sci. Food. Agric., 88(2):248-255.

27-Tasset-Cuevas I, Fernández-Bedmar Z, Lozano-Baena M, Campos-Sánchez $J$, de Haro-Bailón A, Muñoz-Serrano A and AlonsoMoraga A (2013): Protective effect of borage seed oil and gamma linolenic acid on DNA: in vivo and in vitro studies. PLOS One, 8 (2): e56986.

28-Chen-Yang Y, Lu-Te C, Wen-Cheng, H, Chien-Wei H, Dz-Chi C, Kee-Ching GJ and Ting-Yu K (2014): Preventive effects of borage oil and ling-zhi-8 protein on carbon tetrachlorideinduced acute hepatic toxicity in rats. Curr. Topics in Nutraceutical Res., 12(3):91-99.

29-Soliman O, Hafez MN and Abd El Maguid A (2007): Histological and histochemical studies on liver of rats subjected to synergistic effect of natural and synthetic food colorants and/or gamma irradiation. Egypt J. Rad. Sci. Applic., 20 (1):195-214. 
30-Kawashima A, Shimada Y, Nagao T, Ohara $A$, Matsuhisa $A$ and Tominaga $Y$ (2002): Production of structured TAG rich in 1,3dicarpryloyl-2- gamma-linolenoyl glycerol from borage oil. J. Am. Oil Chem. Societ., 79, (9): 871877. 